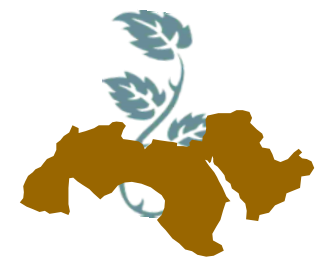

Arab Univ.

J. Agric. Sci., Ain Shams Univ., Cairo, 25(2), 411- 429, 2017

\title{
ANALYTICAL STUDY FOR PREDICTING PRODUCTION, NATIONAL CONSUMPTION AND SELF-SUFFICIENCY RATES OF THE MOST IMPORTANT LEGUME CROPS IN EGYPT
}

\author{
Sanaa H.M. Sadek \\ Statistical Dept., Agricultural Economic Research Institute, Agricultural Research Center, \\ Giza, Egypt
}

Keywords: General time trend models, ARIMA models ${ }^{(1)}$, Tests stationary of time series, Testing unit root, Tests assessing prediction

\section{ABSTRACT}

The United Nations announced in 2016 was as international year for Legumes crops. As a part of sustainable food production, legumes are playing a vital role in Egypt for providing people with their needs from plant protein and amino acids. In general, Egypt suffers a gap between domestic production of legumes and consumption needs, particularly of Faba bean, and lentil. Thus, self sufficiency ratios reached $39 \%$ and $1.6 \%$ for both crops in 2014 respectively ${ }^{(2)}$. Consequently, the imported amounts from both products were increasing during 1993 and 2014. So that the average of import value of Faba bean reached to LE 1.7 milliards alone, while lentil reached to LE 583.4 millions during 2010 and 2014, which represent about $66.2 \%$ and $22.3 \%$ respectively from the average import value of legume crops. Due to spread Balkiros injury in 2011, the cultivated area and domestic production of Faba bean has been significantly declined so that import value was increased. While, Faba bean domestic production represents about $78 \%$ of total legumes production, lentil represents only $1.3 \%$ as average of the period (1993$2014)^{(3)}$.

\footnotetext{
(1) (Autoregressive Integrated Moving Average ).

${ }^{2}$ ) Ministry of Agriculture and land reclamation, economic affairs sector, the Central Administration of Agricultural Economics, Public Administration of agricultural economic resources, food balance sheets, various issues.

$\left({ }^{3}\right)$ Ministry of Agriculture and land reclamation, economic affairs sector, the Central Administration of Agricultural Economics, Foreign trade of agricultural exports and imports Bulletin, various issues.
}

The present paper aims to: (a) Identify the most important productivity and consumption indicators for leguminous crops in Egypt by using the equations of general time trend during the period (19932014). (b) Analyze statistical methods for predicting the most important economic indicators for legumes during the future period (2015-2024). ARIMA models were used to forecast production, consumption, and self-sufficiency after eliminating time series non-stationary and transferring it into stability or stationary series. This was done to be able to use PC-application econometric software package E-views 8 program. (c) Review, explain and interpret the results of ARIMA forecasting and the general time trend models as guidelines to draw agricultural production policy for legumes.

\section{INTRODUCTION}

The most serious problems facing developing countries over the world is food shortages, The General Assembly of United Nations (UN) declared at its 68th session in 2016 as the International Year of pulses, leguminous crops as part of a sustainable food production aimed to achieving food security and nutrition, where pulses provide a vital source of plant protein, amino acids and alternative to meat. It should be eaten as a part of a healthy diet to treat obesity and prevent chronic diseases, also contribute in the animal food.

Recently, Egypt suffers increasing gap between domestic production and national consumption of some pulses such as Faba bean, lentil and dry Kidney Beans crops. This is due to decline of cultivated area and production and while an increases of consumption due to rapid growing population and significant increase in Relative profitability of competitive crops which led farmers to 
grow clover and vegetables at the cost of Faba bean and lentil.

Where, the average legumes area decreases from about 402 thousand Fadden for the period (1993-1997) to about 150.4 thousand Fadden for the period (2010-2014). Particularly, the grown areas of Faba bean and lentil decreased from about 314 and 13 thousand Fadden, respectively during the period (1993-1997). Table (1) ${ }^{(4)}$, Which represents about $78 \%, 3.2 \%$ respectively of the average area of pulses, To about 121.5, 1.69 thousand Fadden respectively. And its represents about $81.5 \%, 1 \%$ respectively of the average area of pulses for the period (2010-2014) Table (1) ${ }^{(5)}$.

\section{METHODOLOGY AND DATA SOURCES}

Statistical analysis using ARIMA technique according to Box-Jenkins time series analysis method -was used to predict variables of production, consumption, and self sufficiency of legume crops in nearly future. It is known that forecasted values using ARIMA techniques takes into account the effects of other independent variables that can be set out in the error term of forecasted equation. (ARIMA) Model characterized by three orders, According to the methodology of Box-Jenkins in time series analysis, denoted as the ( $p, d$, and q), ( $p$ ) is the order of autoregressive, (d) is order of integration, that is the number of differencing operations which make the series stationary and $(q)$ is order of moving average.

\section{Estimation model through four steps}

\section{First step Model Identification}

1. Test stationary time series by estimating the autocorrelation function (ACF), which ranges its value between +1 and -1 and estimate the partial autocorrelation function (PACF) that measures the partial effect of addition lag values in the model according to the Q- Statistics.

2. Procedure testing unit root by Phillips-Perron $\left(\tilde{t}_{\alpha}\right)$, Augmented Dickey Fuller (ADF).

$$
\mathrm{pp}=\tilde{\mathrm{t}}_{\alpha}=\mathrm{t}_{\alpha}\left(\mathrm{Y}_{0} / f_{0}\right)^{1 / 2}-\left[\mathrm{T}\left(f_{0}-Y_{0}\right)(\mathrm{se}(\hat{\alpha})) / 2 f_{0}^{1 / 2} s\right]
$$

(4),(2) Ministry of Agriculture and land reclamation, economic affairs sector, the Central Administration of Agricultural Economics, Public Administration of agricultural economic resources, food balance sheets, various issues. where: $\hat{\alpha}$ is the estimate, ta the $\tilde{\mathrm{t}}$-ratio of $\alpha$, se( $\hat{\alpha})$ is coefficient standard error, and $(s)$ is the standard error of the test regression, $Y_{0}$ is the consistent estimate of the error variance (calculated as $\left.(T-K) s^{2} / T\right)$, and $f_{0}$ is an estimate of the residual at frequency zero.

$$
\begin{gathered}
(A D F)=\Delta \gamma_{t}=\alpha \gamma_{t-1}+x_{t}^{\prime} \delta+\beta_{1} \Delta \gamma_{t-1}+\beta_{2} \Delta \gamma_{t-2}+\ldots \ldots \\
+\beta_{\rho} \Delta \gamma_{t-\rho}+\nu_{t} .
\end{gathered}
$$

\section{Second step Parameter Estimation and Selec-} tion

Selecting the candidate model, that uses to make prediction of the indicators. Through the experience of many of the attempts for the variable under study by models autoregressive, integrated and moving average.

$\Delta Y_{t}=\beta_{0}+\beta_{1} \Delta Y_{t-1}+\ldots .+\beta_{p} \Delta Y_{t-p}+\Delta \varepsilon_{t}+\theta_{1} \Delta \varepsilon_{t-1}+\ldots \ldots+\theta_{q} \Delta \varepsilon_{t-q}$

Where: $\Delta=$ Differences to minimize error term, $\beta_{0}=$ Constant, $\left(\beta_{1}, \beta_{p}, \theta_{1, \ldots \ldots . . .} \theta_{q}\right.$, Coefficient of regression model $),\left(Y_{t-1}, Y_{t-2}, \ldots \ldots . Y_{t-p}, \varepsilon_{t-1}, \varepsilon_{t-q}\right.$ independents variables with number of lag ), $\Delta \varepsilon_{t=}$ Error term.

\section{Third stage Diagnostic Checking}

Different models are examined after the estimation to identify the best estimation accordance to the nature of the data and the significant estimated parameters, in addition to the AIC, SC, HQ criteria.

Akiake Information Criterion $(A I C)=-2(L / T)+2$ $(K / T)$

Schwarz Criterion (SC) $=-2 L / T+(k \log T) / T$

Hannan- Qunin Criterion( $\mathrm{HQ})=-2(L / T)+2 K$ $\log (\log (T)) / T$

Where: $\log -$ Likelihood $(\mathrm{L})=-T / 2\left\{\left(1+\operatorname{Ln}\left(2^{*}\right.\right.\right.$ $\pi)+\ln (R S S / T)\}, T=$ number of observation.

Durbin Watson $(D . W)=\sum_{t=2}^{T}\left(\hat{e}_{t}-\hat{e}_{t-1}\right)^{2} / \sum_{t=1}^{T} \hat{e}_{t}^{2}$

It is the ratio of the sum of squares differences between the values of successive residuals from one to the sum of squares of residuals values $\left(\hat{e}_{t}\right)$.

\section{Fourth step Forecasting}

Forecasting of chosen model by least squares method. Then test the model's ability to predict through tests assessing prediction as Theil's Inequality Coefficient, the lowest value for the 
standards root mean squares Error (RMSE), and Mean Absolute Error(MAE).this methodology BoxJenkins have used in estimating the area, national production, consumption, gap and self-sufficiency ratios for Faba bean and during the period (20152024).

Theil's Inequality Coefficient $T=\sqrt{\frac{\sum\left(d_{\mathrm{e}}-d_{\mathrm{a}}\right)^{2}}{\Sigma d^{2}{ }_{\mathrm{a}}}}$

Where: $d_{\mathrm{e}}=$ Change in the expected value of the dependent variable, $d_{\mathrm{a}}=$ Change in the actual value of the dependent variable.

RMSE $=\sqrt{\frac{\Sigma\left(y_{\mathrm{e}}-y_{\mathrm{a}}\right)^{2}}{n-K}}$

Where:

$y_{\mathrm{e}}=$ Actual value of the dependent variable during the period outside the sample.

$y_{a}=$ The expected value of the dependent variable during the period outside the sample, $\mathrm{n}=$ number of observation, $\mathrm{K}=$ number of parameter.

The research drew its data from official sources of the Ministry of Agriculture and Land Reclamation, Economic Affairs Sector, Central Administration of Agricultural Economics, General Department of Statistics records, the bulletin of foreign trade exports and imports of agricultural statistics, and bulletin food balance. The using of studies and researches related to the field of research, Ministry of Planning, monitoring and administrative reform, in addition site on the web.

\section{RESULTS AND DISCUSSION}

\section{(I) Economic Indicators for current legumes group (Tables 1 and 2)}

(a) Total cultivated area for legumes ranged between a minimum of 106 thousand feddans in 2010 , which represent about $0.7 \%$ of Total Cropped Area ${ }^{(6)}$ and a maximum of 469 thousand feddans in 1998, which represent about $3.4 \%$ of Total Cropped Area $^{(7)}$, reflecting a small relative importunacy of legumes within Egyptian cropping pattern.

\footnotetext{
${ }^{(6,2)}$ Ministry of Agriculture and land reclamation, economic affairs sector, the Central Administration of Agricultural Economics, Public Administration of agricultural economic resources, statistical agricultural sheets, various issues, 1998,2010
}

(b) Faba Bean is the most important crop within legumes in Egypt, representing in a minimum of ca. $66 \%$ in 2002 and a maximum of ca. $85 \%$ in 2014.

(c) Lentil is the second imported crop and the fourth important crop with ca.1.3\% of total cultivated legume area on average of $1993-2014$.

(d) With exception of 6 years 1996 - 2001, Faba beans production cover domestic consumption and there was a surplus in production, so that the gap was ranging between 445 thousand metric ton in 2008 as maximum and 8 thousand metric tons in 1994, averaging ca.134 thousand metric ton for the whole period of time between 1993 and 2014.

(e) Production of both Faba bean and lentil have witnessed decreasing time trends of about 9.85 thousand and 0.31 thousand metric tons respectively (Table 2). This is due to significantly decreasing time trends of cultivated areas for both crops. An important reason for the decreasing trend in Faba bean area is due to 2011 spreading jury of "Mosaic Faba bean virus" "Balkiros" in the most important the provinces of Upper Egypt, especially in the governorates of Minya and Assiut, Which caused loss for Faba bean farmers, led to the reluctance of farmers for the cultivation of this crop. Table 1 shows a significant time trend decrease in cultivated area of Faba bean during the period (1993-2014). Faba bean and lentil areas were declined from about 314 and 12.7 thousand Feddan as an average of 1993- 1997 to about 121.5 and 1.7 thousand Feddan as an average of 2010- 2014 of both crops respectively. The estimated determination coefficient indicates that $80 \%$ of the changes in the Faba bean area are explained due to the factors that reflected the element of time (Table 2).

(f) The profitability per unit of land among winter competitive crops is one of the most important factors that have played a role of keeping grown area of Faba bean on its minimum.

(g) As result of rapid population growth national consumption of both Faba bean and lentil has increased and thus the value of imports to ca. 273 and 83 thousand tons annually on average in last 22 years. This has increased the burden on both the trade balance and the Egyptian balance of payments (Table 1).

(h) Time trends were statistically estimated for the economic indicators of Faba bean and lentil and the results are shown in Table (2). In general, the results indicate decreased time trends 
of area, production, and self-sufficiency of ca. 12 thousand Feddan, 10 thousand ton, and $3.4 \%$ decrease of self-sufficiency ratio for Faba bean and similarly 0.667 thousand Feddan, 0.452 thousand ton, and $0.72 \%$ decreasing in self-sufficiency ratio of lentil. With decreasing an annual rate growth of about $12.28 \%, 11.3 \%$, $12.7 \%$ of the average of the cultivated area, production and self-sufficiency ratio of lentil.

(i) The results in Table 2 indicates that the national consumption and the gap that also has taken the decreasing trend, amounted to about $7.631,17.482$ thousand tons respectively during the period, at an annual growth rate an increasing amounted about $1.75 \%, 13.05 \%$ of the annual average for national consumption and gap of Faba bean.

(j) As it is clear also that the high ratio of the loss of Faba bean, which represents about $23.7 \%$ of average total other uses, which amounting to about 122 thousand tons during the period. Therefore, the Egypt loses part of the production can provide by reducing the size of the losses to fill part of the needs of national consumption.

(k) As it turns out that the total other uses of lentil has taken decreasing general trend. Total other uses of lentil depends on the size of the losses ,the seed ,heading for industry amounting about 3.7, 0.4, 0.02 thousand tons, representing each about $89 \%, 10.5 \%, 0.5 \%$ respectively of average total other uses, amounting about 4.1 thousand tons during the study period.

(I) As the same table indicates that imports of lentil in the same period of the study has taken an increasing general trend, amounted to about 1.214 thousand tons, growing at an annual growth rate of about $1.46 \%$.

(m)All regression coefficients and statistical fitness of estimated models were significant at level 0.05. As shown in Table 2, all T-test values, Ftest and $R^{2}$ values were significantly proved.

(II) Prediction of Faba Bean Production Indicators until 2024 using ARIMA* \& General Trend Models

1. The first scenario is the most pessimistic model for area ,production and self- sufficiency ratio of Faba bean:

a) The Tables No. (3), (4), (5) and Equation (1) indicates to the continuing decrease in the predicted total area of the Faba bean using ARIMA model $(1,0,0)$ during the period (2015-
2024), where the area is predict to reach 11.818 thousand Feddan, ranging from a maximum of about 90 thousand Feddan and a minimum of about 66.6 thousand Feddan in 2020.

b) Predicted area using ARIMA technique is lower than that of using a general time trend model, expecting to reach ca. 39.6 thousand Feddan in 2020.

The results of ARIMA model are more accurate those of the general time trend model, through the stability and stationary for time series, than select the best models according to the criteria AIC, SC, where amounted to (10.398), (10.497) respectively. As the most important problems of measurement have been eliminated, where amounted the value of the Test Durbin Watson (about 2.359), as well as the criteria of the evaluating the model's ability on predict such as the value of Theil's coefficient amounting to about (0.057), the value of root mean squared-errors amounting to about (28.486) and the value of the mean absolute -errors amounting to about (22.394). Where the ARIMA a dynamic model that takes effect the rest of the other variables on the dependent variable.

c) The Tables No. (3), (4), (5) and Equation (2) using ARIMA model $(2,0,0)$ predicted estimation for Faba bean production in 2020 would amount ca. 17.274 thousand tons, ranging from a maximum of about 128.83 thousand tons and a minimum of about -94.286 thousand tons when using ARIMA model, but 129.972 thousand when using general time trend.

d) The criteria AIC, SC for Faba bean production amounted to (11.06), (11.21) respectively, and the value of the Test Durbin Watson (about 2.22), the Theil's coefficient amounting to about (0.055), as well as the value of root mean squared-errors and the value of the mean absolute -errors amounting to about (36.435), (28.205) respectively.

e) Showing also from the same tables and Equation (3) the continued decrease in the Predicted self-sufficiency ratio of Faba bean by using ARIMA model $(0,0,1)$ during the same period, that amounts to about $3.08 \%$ in 2020 .while using a general time trend model, expecting to reach ca. $15.8 \%$ in 2020 .

f) The criteria AIC, SC, the value of the Test Durbin Watson, the Theil's coefficient, the value of root mean squared-errors and the value of the mean absolute -errors for Faba bean selfsufficiency ratio those of amounting to about (9.51), (9.61), (2.19), (0.107), (17.356), (13.575) respectively. 
legume crops in Egypt 
2. The second scenario is the most optimistic model for Faba bean production and Selfsufficiency ratio:

a. The Tables No. (3), (4), (6) and Equation (4) indicates to the continuing decrease in the Predicted estimation for Faba bean production using ARIMA model $(0,0,1)$ during the period (2015-2024), where production is predict to reach ca.13.58 thousand tons, ranging from a maximum of about 138.7 thousand tons and a minimum of about -111.5 thousand ton in 2024 .

b. Predicted production using ARIMA technique is lower than that of using a general time trend model, expecting to reach ca. 90.57 thousand tons in 2024.

c. According to the criteria for assessing and criteria of the evaluating the model's ability on predict to ARIMA model is good, where the criteria AIC, SC, where amounted to (11.314), (11.464) respectively, the value of the Test Durbin Watson (about 2.409), the value of Theil's coefficient amounting to about (0.062), as well as the value of root mean squarederrors and the value of the mean absolute errors amounting to about (59.398), (46.617).

d. Showing also from the same tables and Equation (5) the continued decrease in the Predicted self-sufficiency ratio of Faba bean by using ARIMA model $(3,0,2)$ during the same period, that amounts to about $14.9 \%$ in 2024 .while using a general time trend model, expecting to reach ca. $2.1 \%$ in 2024.

e. According to the criteria for assessing and criteria of the evaluating the model's ability on predict to ARIMA model is beater than that of using a general time trend model, where the criteria AIC, SC, the value of the Test Durbin Watson, the Theil's coefficient, the value of root mean squared-errors and the value of the mean absolute -errors for Faba bean self-sufficiency ratio those of amounting to about (7.257), (7.06), (2.208), (0.547), (8.794) and (6.123) respectively.

f. According to ARIMA model, the area of Faba beans will decrease until reaching its minimum in 2020. Socio-economic variables such as real income, produced prices, new varieties, new production technology must be investigated to overcome negative impacts of lower predicted area of Faba bean in 2020 for the first scenario that is the most pessimistic model

g. As clear from previous results, ARIMA model are more accurate than those of the general time trend model, after transform time series to the stability and stationary series, and according to using criteria of the evaluating the model's ability on predict and criteria assessing model for two scenarios to Faba bean production and self-sufficiency.

\section{Prediction of National consumption and Gap of} Faba bean:

a. Equation (6) in the Tables No. (3), (4) and Table (7) summarize the results of ARIMA prediction for national consumption of Faba bean using ARIMA model $(0,0,1)$ during the same period, and refers to the continuing increase that amounts to about 561.768 thousand tons, ranging from a maximum of about 888.7 thousand tons and a minimum of about 234.8 thousand tons in 2024.

b. As it is clear the estimate of the predicted national consumption by using ARIMA model approaching from the predicted by using general time trend model, expecting to reach ca. 593,25 thousand tons in 2024.

c. The criteria AIC, SC for Faba bean national consumption amounted to (12.17), (12.27) respectively, and the value of the Test Durbin Watson (about 1.90), the Theil's coefficient amounting to about (0.116), as well as the value of root mean squared-errors and the value of the mean absolute -errors amounting to about (103.87), (81.21) respectively.

d. Equation (7) in the same tables summarize the results of ARIMA prediction for size of the gap of Faba bean using ARIMA model $(1,0,1)$ during the same period ,that would reach to ca.560 thousand tons, ranging from a maximum of about 818.42 thousand tons and a minimum of about 301.58 thousand tons in 2024 .

e. As shown decline in estimation of the predicted gap using ARIMA model about the estimation using a general time trend amounting to about 492.83 thousand tons in 2024.

f. According to the criteria for assessing and criteria of the evaluating the model's ability on predict to ARIMA model is beater than that of using a general time trend model, where the criteria AIC, SC, the value of the Test Durbin Watson, the Theil's coefficient, the value of root mean squared-errors and the value of the mean absolute -errors for Faba bean self-sufficiency ratio those of amounting to about (7.257), (7.06), (1.91), (0.254), (96.195) and (80.63) respectively. 
(III) Prediction of lentil Production Indicators until 2024 using ARIMA* \& General Trend Models

1. Prediction of area,production and National consumption of lentil

a) Equations 8 and 9 in Table No. (3), (4) and (8) summarize the results of ARIMA prediction for lentil. Predicted production and area would reach its maximum in 2024.

b) It is clear from ARIMA model takes technique the First differencing operation for prediction area and production of lentil, which makes the series stability and stationary.

c) ARIMA model $(0,1,2)$ indicates to the continuing increase in the predicted area of lentil, expecting to reach ca. 0.644 thousand Feddan in 2024. while it is clear the estimates of the predicted area continuing to decreased by using general time trend during the predicted period.

d) As clear from previous results of ARIMA mod$\mathrm{el}$, that the total predicted area of the lentil crop will be increasing very slightly, during the future period.

e) The results of the criteria AIC, SC for lentil prediction area amounted to (3.651), (3.799) respectively, the value of the Test Durbin Watson, the Theil's coefficient, the value of root mean squared-errors and the value of the mean absolute -errors those of amounting to about (2.223), (0.566), (1.731) and (1.226) respectively.

f) As It is clear from the same tables predicted lentil production in 2024 would amount ca. 0.498 thousand tons when using ARIMA model $(2,1,1)$ but continuing to decline when using general time trend during the predicted period.

g) The results of the criteria AIC, SC for lentil prediction production amounted to (2.55), (2.75) respectively. the value of the Test Durbin Watson, the Theil's coefficient, the value of root mean squared-errors and the value of the mean absolute - errors those of amounting to about (2.031), (0.578), (0.716) and (0.578) respectively.

h) Equation 10 in Table No. (3), (4) and (8) summarize the results of ARIMA prediction for lentil. Predicted national consumption would reach its maximum in 2024 when using ARIMA model $(0,0,2)$, that amounts to about 85.046 thousand tons, ranging from a maximum of about 108.786 thousand tons and a minimum of about 61.306 thousand tons in 2024 . i) The estimate of the predicted consumption by using ARIMA model approaching from the expected estimate when using general time trend. So expecting to reach ca.84.217 thousand tons in 2024.

j) The results of the criteria AIC, SC for lentil prediction consumption amounted to (8.815), (9.96), respectively. the value of the Test Durbin Watson, the Theil's coefficient, the value of root mean squared-errors and the value of the mean absolute - errors those of amounting to about (1.95), (0.112),), (17.768)) and (14.218) respectively.

\section{Prediction of Gap and self- sufficiency ratio of lentil}

a) Equations 11 and 12 in Table No. (3), (4) and (8) summarize the results of ARIMA prediction for lentil. Predicted gap and self-sufficiency ratio would reach its maximum in 2024.

b) As shown in Table (9) the continuous increase in the predicted gap of lentil when using the ARIMA model $(0,0,2)$, where the size of the expected gap ca. 88.887 thousand tons, ranging from a maximum of about 139.171 thousand tons and a minimum of about 38.603 thousand tons in 2024.

c) The predicted gap by using ARIMA model $(0,0,2)$ approaching from the predicted estimate by using general time trend amounting to about 89.477 thousand tons in 2024.

d) The criteria AIC, SC, where amounted to (8.862), (9.01), respectively. As the value of the Durbin Watson Test amounted (about 1.99), the Theil's coefficient amounting to about (0.119), as well as the value of root mean squared-errors amounting to about (17.943), and the value of the mean absolute -errors amounting to about (14.632).

e) As also shown in Table (9) ARIMA model takes technique the First differencing operation and continuous a slight increase in the predicted self-sufficiency ratio of lentil when using the ARIMA model $(0,1,2)$, where the expected predicted ca. $0.75 \%$,ranging from a maximum of about $4.73 \%$ and a minimum of about $-3.23 \%$ in 2024. While continuous decline when using general time trend through the same period of prediction.

f) The criteria AIC, SC, Durbin Watson Test, Theil's coefficient where those of amounted to (5.43), (5.58), (1.94), (0.845), as well as the value of root mean squared-errors and the mean absolute -errors amounting to about (3.577), (1.722) respectively. 


\section{CONCLUSIONS}

Major findings of existing study are when comparing the results of ARIMA models with those gained by the general time trend models, shows an agreement between the results of the predicted estimates resulted by ARIMA and general time trend models with the exception of the predicted estimates of area, production and self-sufficiency ratios for lentil crop, where was found that the predicted results by ARIMA models reverse the predicted results by general time trend models.

Reasons are due to converting time-series to stability and stationary chains during the study period by applying autoregressive, integration which make the number of differencing operations, moving average, and after eliminated the most important problems of Econometrics and tests the modeling accuracy which has been proven according to the criteria of the evaluating the ability of the model on predict. Than ARIMA results seem to be more accurate. So the study suggests relying on ARIMA to predict production and consumption for important crops.

Existing study shows also decreased predicted values of production of Faba bean, reaching 13.578 thousand tons in 2024 according to the second scenario. This is to be compared with increased predicted consumption value of about 561.768 thousand tons at the end of forecasting period in 2024. Consequently, the size of the food gap will continue increasing to reach about 559.999 thousand tons in 2024. Ratio of selfsufficiency would be affected adversely achieving its lowest value at about $2.109 \%$ in 2024 .

As for lentil, ARIMA model predicted grown area (and production) would be about 0.644 thousand Feddan (0.498 thousand tons) in 2024. Meanwhile, consumption of lentil would also increase at about 85.05 thousand tons in 2024 .

It leads to increase in the size of the gap between production and consumption, that affecting negatively on achieved self-sufficiency ratio where, the results showed the continued increasing size of the predicted gap reaching about 88.89 thousand tons in 2024, while increasing self-sufficiency slight increase almost to contact to about $1 \%$ in the same year.

Generally speaking that Egypt will depend mainly in the future period (2015 -2024) on imports, in the provision of food needs of leguminous crops (beans and lentil), Resulting in a decline in the trade balance and balance of Egyptian payments. But regarding the plan approved by the
Government to increase the agricultural area of about 1.5 million Feddan, it is expected selfsufficient rates will rise in some agricultural crops, according to the plan.

\section{RECOMMENDATION}

- It is suggested that the area of legumes, especially Faba bean and lentil, as explained in research decreasing the total pulses area, should be increased so we need to allocate area for the cultivation of leguminous crops is estimated at about 213.6, 112.8 thousand Feddan for crops of Faba bean and lentil, that equivalent of about $14.24 \%, 7.5 \%$ of new agricultural land (a million and a half Feddan) from Development project of the 4 million-Feddan, in the case of constant productivity, This is due to high its nutritional importance, in addition to the importance of leguminous crops to improve soil properties and therefore not to use synthetic $\mathrm{Ni}$ trogen fertilizer in the planting of legumes which reduces environmental pollution. along with filling portion of food imports, which accounted for about $62.5 \%, 89 \%$ of the total consumption of Faba bean and lentil, which represents a burden on the balance of Egyptian payments.

- The need to activate the role of Field Crops and Plant Pathology Research Institute in the fight against virus "Mosaic Faba bean" beside the importance of the role of agricultural extension to treat the problems facing the Faba bean farmers.

- Directing scientific research to produce highyield varieties, which are appropriate for the new land to increase the national production of leguminous crops.

- It is clear from the previous results, the wastage ratios from Faba bean and lentil are estimated at $23.7 \%, 0.89 \%$ respectively. Therefore, the government must inject investments to reduce wastage an minimize the gap between national consumption and production, through improving the storage and harvesting methods

- Setting pricing policy that encourages farmers to cultivated these crops, through adopt policies farmers support, as well as the tendency towards contract farming and establishment department of databases, that provides information for farmers about cultivated area that hopeful, optional cropping patterns at the level of the republic, and prices that to guide farmers in order to increase production and reduce dependence on imports 
- Should dependence on statistical models to predict in future studies as a guide to give the most accurate indicators useful in agricultural policy-making and put plans for production and investment to rationalize the financial and economic decisions for agricultural policies planners and decision -makers.

\section{REFERENCES}

Abd Elkader M.A. Abd Elkader 1996. "Econometric Theory and Practice", Faculty of Commerce, University of Alexandria, $2^{\text {nd }}$ pp. 410-460.

Osman W. and El-oud M. 2011. "Box-Jenkins Methodology of Time Series Analysis and Forecasting" University of Damascus, Economic and Legal Sciences Journal, 27, 127-134.

Kumar M. and Anand M. 2012. "An Application of time series ARIMA Forecasting Model for Predicting Sugarcane Production in India "studies in Business and Economics, pp. 81-94.

Safiya Z. Ismail 2007. "Prices of farm and Recent trends in Estimating and forecasting" a reference search provider for promotion to the head Chief of Research, Agricultural Economics Research Institute, pp. 66-86.

Abbas, A.F. 2009. "Forecasting and Smoothing time series using the transfers with the application" The Second Practical Conference of
Mathematics -Statistics and Informatics of the University of Mosul - Faculty of Computing and Mathematical Sciences, Iraq. pp. 503-517.

Eviews 9 for Window, 2015. Quantitative Micro Software LLC, USA.

EViews 7 User's Guide II, 2010. Quantitative Micro Software, LLC, United States of America, $111 \mathrm{p}$.

Robert, P. and Danial, R. 1991. Econometric Models and Economic Forecasts, Univariate Forecasting Methods, $3^{\text {rd }}$ Ed., McGraw-Hill, Inc.

Ministry of Agriculture and Land Reclamation, 1993-2014. Economic affairs sector, the Central Administration of Agricultural Economics, the General Directorate of Agriculture Statistics, Agricultural Statistics Bulletin, various issues.

Ministry of Agriculture and Land Reclamation, 1993-2014. Economic affairs sector, the Central Administration of Agricultural Economics, Public Administration of agricultural economic resources, food balance Bulletin, various issues.

Ministry of Planning, Monitoring and Administrative Reform, 1993-2014. Economic and social development Plan for the fiscal year 15/2016, Part V, Economic Development, pp. 165-182. 